\title{
NEUROCITOMA NO SISTEMA NERVOSO CENTRAL
}

\author{
José Torquato Severo* \\ Lígia Maria B. Coutinho ** \\ Luiz Carlos TeIXeIra *** \\ Mario Ferreira CoUtinho **** \\ ADÃo ANICET *****
}

Os tumores das células nervosas foram denominados por Virchow (1864) de neuromas gangliocelulares. Desde essa época tais neoplasias tem recebido várias denominações: ganglioneuromas ${ }^{3}$, neurocitomas ${ }^{7}$, gangliomas ${ }^{5}$, neuroastrocitoma ${ }^{10}$ e gangliocitoma ${ }^{17}$. As diversas denominações desse tipo de tumor refletem o pequeno conhecimento que se tem desse processo blastomatoso, devido à raridade da ocorrência, ao considerar-se a sua localização no sistema nervoso central e ao escasso número de casos estudados na literatura $1,4,5,13,14$.

O primeiro caso de tumor neuronal de localização no sistema nervoso periférico foi estudado por Loretz ${ }^{12}$ em 1870 e somente em 1901 Worcester ${ }^{16}$ publicou o primeiro trabalho com comprometimento encefálico. Globus ${ }^{9}$ afirmou, em 1938, que os glioneuromas supratentoriais e os espongioblastomas constituiriam um pouco mais de $12 \%$ do número total dos tumores supratentoriais de origem neuroectodérmica, não sendo, portanto, tão raros.

Os neurocitomas são mais freqüentes no adolescente e adulto jovem, não havendo predominância quanto ao sexo. Macroscopicamente, esses tumores são pequenos, firmes, bem delimitados, podendo apresentar focos de calcificação e, freqüentemente, sofrem degeneração cística ${ }^{1}$. Histologicamente, caracterizam-se por serem formados por células nervosas maduras, apresentando um estroma constituiído por tecido neuróglico e fibras nervosas. Podem ser encontrados tumores em que os elementos predominantes são as células ganglonares e, outros, em que estas são relativamente escassas. Esses dois extremos estão ligados por variações histológicas e, muitas vezes, estas podem coexistir num espécimen único ${ }^{14}$.

Os tumores de células nervosas, tanto periféricos quanto centrais, possuem pontos em comum, mas diferem fundamentalmente no caráter de seus estromas. Aqueles que ocupam o sistema nervoso central possuem o estroma formado essencialmente por tecido glial e vasos sangüíneos, em contraste com os periféricos, nos quais as células de Schwann fazem o mesmo papel ${ }^{14}$.

Trabalho realizado no Serviço de Neurologia e Neurocirurgia do Hospital Santo Antonio, apresentado no IX Congresso Brasileiro de Neurocirurgia (Rio de Janeiro, julho-1972): * Médico residente; ** Neuropatologista; *** Neurocirurgião; $* * * *$ Chefe do Serviço; ***** Neurorradiologista. 


\section{O B SER VAC A O}

S.H., de sexo feminino, com 6 anos de idade, branca, registro n.9 9686, foi hospitalizada em 03-07-1971 com queixas de cefaléias e vômitos iniciados há 30 dias. Há 4 dias começara a apresentar distúrbios visuais e grande dificuldade na deambulação, além de cefaléia e vômitos incontroláveis. Exame neurológico - Paciente em coma leve, muito agitada, apresentando dilatação pupilar e discreta rigidez de nuca. A fundoscopia revelou edema de papila bilateral. Exame do liquido cefalorraqueano: punção lombar; pressão inicial de $56 \mathrm{~cm}$ de água; líquido límpido; exames citoquimicos normais. Punção ventricular: durante sua realização, encontrou-se o hemisfério cerebral direito de consistência aumentada; após várias tentativas infrutíferas para punçāo do ventrículo lateral direito, foi puncionado um cisto dando escoamento a pequena quantidade de líquido espêsso, viscoso, fortemente xantocrômico. Angiografia carotídea direita: revelou volumoso processo expansivo frontal, parcialmente cístico, com vasos de neoformação e hérnias de hipocampo, sob a foice e retro-alar descendente.

Intervenção cirúrgica - Realizada craneotomia bifrontal, observou-se meninge e cérebro não pulsátil. Após a abertura da dura-mater, várias punções foram feitas no lobo frontal direito, obtendo-se líquido xantocrômico em algumas e, em outras, liquido de cor de chocolate. Encontrou-se um tumor frontal que ultrapassava a linha média, comprometendo os lobos temporal e parietal direitos. O lobo frontal encontrava-se totalmente invadido pelo tumor que se estendia até a base do crânio. A tumoração era policística, apresentando-se ora bem delimitada, sendo facilmente dissecável, era infiltrante. Algumas áreas eram duras e esbranquiçadas e, outras, mais moles e de cor cinza. O tumor era muito vascularizado e, durante a ressecção, a paciente entrou em choque por parada cardiaca irreversivel.
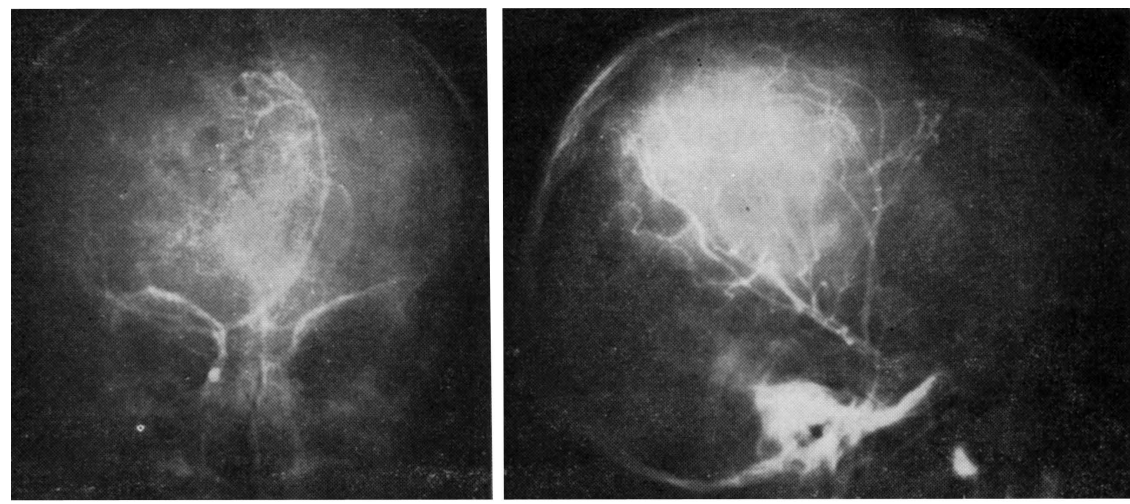

Fig. 1 - Caso S.H. Ȧ esquerda, angiografia carotidea direita mostrando artéria pericalosa fortemente desviada para a esquerda e deformada em arco com concavidade direita; à direita, angiografia carotídea direita mostrando a bifurcação carotídea e a artéria pericalosa desviada para trás e área no lobo frontal com vasos neoformados. 


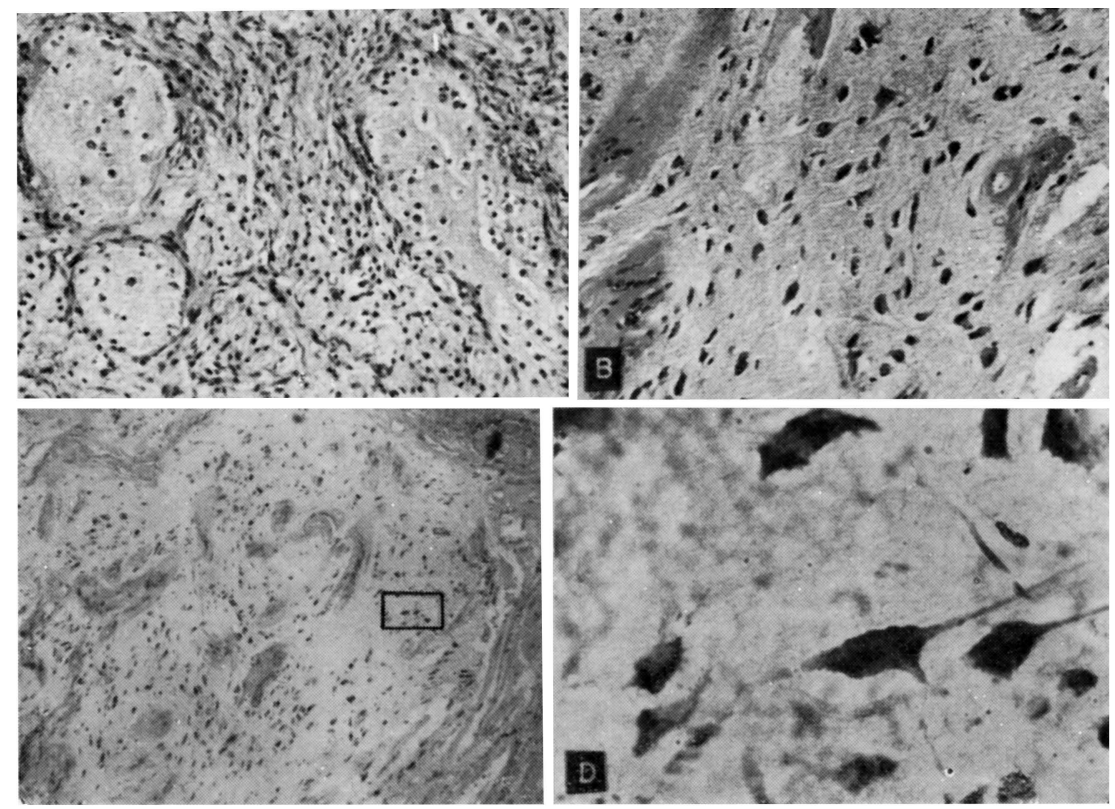

Fig. 2 - Caso S.H. Em A, ninhos celulares rodeados por rico estroma fibroglial (H.E. x100); em B, células nervosas maduras atipicas, com núcleos vesiculosos e leptocromáticos, apresentando prolongamentos citoplasmáticos (H.E. x100); em C, área do tumor constituida predominantemente pelas células tumorais, com escasso estroma fibroglial (H.E. x35); em D, aumento maior da área assinalada na figura anterior (H.E. $\left.x_{4} 00\right)$.

Exame histo-patológico do material retirado por biópsia - Tumor constituido por células de núcleo arredondado, com cromatina frouxa, citoplasma claro, dispostas em ninhos delimitados por tecido neuróglico, rico em fibras. Algumas dessas células possuem prolongamentos e numerosos grânulos que se coram pela técnica de Nissl. Esses grânulos se encontram junto à membrana citoplasmática, nas proximidades da área onde nasce o prolongamento celular maior. Conclusão: Neurocitoma.

\section{COMENTARIOS}

E discutivel o papel que o estroma tumoral representa. Para alguns autores ele seria participante do processo blastomatoso enquanto que, para outros, seria apenas a estrutura de sustentação das células tumorais. Concordamos com a segunda afirmação, adotando a nomenclatura de Del Rio Hortega $^{7}$ para tais tumores.

Os neurocitomas são mais encontradiços no sistema nervoso periférico, sendo mais raros no sistema nervoso central. Esses tumores encefálicos se 
localizam nas áreas basais, nos hemisféricos cerebrais, sendo o lobo temporal o mais freqüentemente comprometido ${ }^{1}$. No caso ora estudado, a neoplasia se localizava predominantemente no lobo frontal, comprometendo também o parietal e o temporal, extendendo-se até as porções basais do encéfalo.

Os tumores de células nervosas maduras são mais freqüentemente encontrados em adolescentes e adultos jovens. Entretanto, o presente caso é de uma menina de apenas 6 anos de idade. Antunes ${ }^{2}$, em 1949, encontrou 6 pacientes com menos de 10 anos num total de 69 casos de neurocitomas revisados na literatura. Russel e col. ${ }^{14}$ descreveram um caso em criança de dois meses de idade com sintomas presentes desde o nascimento.

O diagnóstico histo-patológico pode, às vezes, ser difícil e alguns critérios devem ser considerados : o reconhecimento de células de origem gangliônica inequívoca ${ }^{14}$, com a presença de núcleo grande, vesiculoso, redondo, contendo um ou mais nucléolos, com cromatina frouxa, bem como a observação de neurofibrilas e de substância de Nissl nas células blastomatosas mais maduras ${ }^{11}$; a evidência de que essas células ganglionares são participantes da neoplasia e não constituintes de um processo de inclusão neuronal por tumor de origem glial ${ }^{14}$; a identificação de células precursoras ${ }^{14}$.

As células ganglionares originadas na crista neural percorrem distâncias maiores durante a vida embrionária, comparativamente àquelas situadas no neuro-eixo. Durante esse processo de migração celular algumas células podem ficar retidas em algum ponto do trajeto. Essas células detidas em sua natural evolução dariam origem, mais tarde, segundo Cohnheim, a processos blastomatosos. É evidente que, quanto maior for o trajeto que as células embrionárias devem percorrer até atingirem o seu objetivo, maior será a possibidade de que algumas permaneçam no caminho. Este fato poderia explicar a maior freqüência dos tumores de células nervosas no sistema nervoso periférico do que no sistema nervoso central ${ }^{5}$.

Um neurocitoma pode ser o resultado de uma transformação benigna de um neuroblastoma. Essa transformação ou maturação já foi descrita por diversos autores ${ }^{6}, 8,15$. Segundo Dyke $^{8}$, o mecanismo de diferenciação dos neuroblastomas ocorreria quando da irradiação terapêutica. Esta iniciaria a natural diferenciação, destruiria células imaturas, com sobrevida das mais diferenciadas (resistentes) ou inibiria o fator estimulante da proliferação neuroblástica.

\section{R E S U M O}

E relatado o caso de uma paciente com 6 anos de idade, hospitalizada com síndrome de hipertensão intracraniana. Após o exame neuro-radiológico que evidenciou processo expansivo frontal direito, a paciente foi submetida à cirurgia, durante a qual ocorreu o óbito. O exame histo-patológico do material retirado durante o ato oferatório, permitiu o diagnóstico de neurocitoma, tumor raro no sistema nervoso central. 


\section{S U M M A R Y}

Neurocytoma in the central nervous system: a case report.

The case of a six years old female with intracranial hypertension is reported. After neuro-radiological examination which showed a frontal expansive process at the right side of the brain the patient was operated and died during this intervention. The hystopathological examination of the part of the tissue removed from the tumor revealed a neurocytoma, a rare tumor of the central nervous system.

\section{REF E R E N I A S}

1. ALPERS, B. J. \& GRANT, F. F. - The ganglioneuroma of the central nervous system. Arch. Neurol. Psycniat. (Chicago) 26:501, 1931.

3. ANTUNES, L. - Cit. por CHRISTENSEN 4 .

3. BAILEY, F. \& CUSHING, .H. - A Classification of the Tumors of the Glioma Group on a Histogenetic Basis with a Correlated Study of Prognosis. J. B. Lippincott Co., Philadelphia, 1962, pág. 92-94.

4. CHRISTENSEN, E. - Pathology of the Central Nervous System. Vol. 2. McGrawHill Book Co., New York, 1971, pág. 2081-2C93.

5. COURVILle, C. B. - Ganglioma: tumor of the central nervous system. Review of the literature and report of two cases. Arch. Neurol. Psychiat. (Chicago) $24: 439,1930$.

6. DICK, J. H. N. - Cerebral medulloepithelioma with maturation into ependimal cells and ganglion cells. J. Neuropath. \& Exper. Neurol. 24:442, 1930.

7. DEL RIO HORTEGA, P. - Anatomia Microscopica de los Tumores del Sistema Nervioso Central y Periferico. Blass S. A., Madrid, 1933, pág. 112-117.

8. DYKE, P. C. \& MULKEY, D. A. - Maturation of ganglioneuroblastoma to ganglioneuroma. Cancer 20:1343, 1967.

9. GLOBUS - Cit. por RUSSEL \& col.14.

10. KERNOHAN, J. W. \& SAYRE, C. P. - Cit. por ZULCH ${ }^{17}$.

11. KUHLENBECK, H. \& HAYMAKER, W. - Cit. por CHRISTENSEN ${ }^{4}$.

12. LORETZ, W. - Cit. por COURVILLE s.

13. MAFFEI, W. E. \& GAMA, C. - Estudo anatomo-clínico de um ganglioneuroma in iracraniano. Rev. Neurol. Psiquiat. São Paulo 7:56, 1941.

14. RUSSEL, D. S.; RUBINSTEIN, L. J. \& LUMSDEN, C. E. - Pathology of Tumors $O^{\circ}$ the Nervous System. $2 .^{\circ}$ edição. Edward Arnold Ltd., London, 1959, pag. 162-169.

15. WILKERSQN, J. A.; VAN DE WATER, J. M. \& GOEPFERT, H. - Role of embryonic induction in benign transformation of neuroblastom. Cancer 20:1335, 1967.

16. WORCESTER, W. C. - Cit. por COURVILLE ${ }^{5}$.

17. ZULCH, K. J. - Brain Tumors: Their Biology-and Pathology 2.9 ed. New York Springer Publishing Co. Inc., New York, 1965.

Hospital da Beneficência Portuguesa - Av. Independência $270-90000$ Porto Alegre RS - Brasil. 